\title{
STUDI MULTIKULTURAL PADA ORNAMEN BALI PEPATRAAN: PATRA CINA
}

\author{
Febry Maharlika \\ (Email: febry.maharlika@email.unikom.ac.id) \\ Program Studi Desain Interior \\ Fakultas Desain \\ Universitas Komputer Indonesia \\ Jl. Dipatiukur No.102-116, Bandung, Indonesia
}

\begin{abstract}
ABSTRAK
Ornamen merupakan salah satu elemen dekoratif yang tidak dapat dipisahkan dari kebudayaan Bali. Selain sebagai ragam hias, ornamen juga mengandung muatan filosofis khususnya bagi umat Hindu di Bali. Salah satu jenis ornamen Bali yang cukup dikenal adalah pepatraan. Pepatraan yang diterapkan pada bangunan tradisional Bali selain dihasilkan dari kreatifitas sangging, juga didapatkan dari hasil akulturasi antara budaya lokal dengan budaya lain yang masuk ke Bali, salah satunya adalah patra cina. Patra cina dapat ditemukan pada bangunan-bangunan tradisional Bali sebagai elemen dekoratif yang ditempatkan diantara ornamen khas Bali lainnya. Penelitian ini menguraikan salah satu produk budaya lokal yang terbentuk karena pengaruh datangnya bangsa lain ke pulau Bali. Dengan metode kualitatif interpretatif, bentuk patra cina diuraikan, kemudian dikaitkan dengan pola dasar tradisional Indonesia. Selain itu, pada penelitian ini diuraikan pula kesejarahan patra cina yang diduga berasal dari negeri Cina.Dari hasil analisis bentuk dan kesejarahan dari patra cina maka didapatkan kesimpulan bahwa patra cina merupakan patra yang pola bentuk dasarnya mengacu pada pola bentuk tradisional Indonesia, akan tetapi mengambil bentuk Bunga Sepatu yang berasal dari Cina. Manfaat penelitian ini adalah untuk menambah khasanah ilmu pengetahuan mengenai nilai-nilai yang terkandung dari ornamen patra cina sebagai karya seni tradisional yang tercipta dari proses akulturasi budaya Bali dan Cina.
\end{abstract}

Kata kunci: Bali; Multikultur; Ornamen; Patra Cina.

\begin{abstract}
Ornaments are one of the decorative elements that can not be separated from Balinese culture. In addition to decoration, ornaments also contain philosophical content, especially for Hindus in Bali. One type of Balinese ornament is well known is pepatraan. Pepatraan applied to traditional Balinese building by sangging creativity, also obtained from acculturation result between a local culture with other culture that came to Bali, one of them is patra china. Patra china can be found in traditional Balinese buildings as a decorative element placed among other Balinese ornaments. This study describes one of the local cultural products formed by the influence of other nations. A Form of Patra china is described with qualitative interpretative method then attributed to traditional Indonesian archetype. This study also described the history of Patra China, which allegedly originated from China. From the analysis of the form and history of the Patra china, it is concluded that the Patra china is a patra whose basic pattern refers to the pattern of the traditional form of Indonesia, but takes the form Flower Shoes originating from China. The benefit of this research is to developing knowledge about the values contained from patra china ornament as a traditional artwork which created from the process of acculturation of Balinese and Chinese culture.
\end{abstract}

Keywords: Bali; multicultural; ornament; patra china. 


\section{PENDAHULUAN}

Ornamen tradisional Bali merupakan salah satu ragam hias Indonesia yang mengandung nilai filosofis yang tinggi. Nilai- nilai tersebut adalah representasi dari pemahaman masyarakat Bali mengenai kehidupan, yang menyatu dengan ajaran agama serta kerpercayaannya. Ornamen Bali banyak ditemukan pada arsitektur tradisional Bali, yang menempatkan ornamen sebagai struktur maupun sebagai elemen dekoratif.

Berdasarkan bentuknya, ornamen Bali terdiri dari ornamen flora, fauna, alam, agama dan kepercayaan. Segala ornamen yang ada merupakan perwujudan dari keindahan manusia dan alam yang termanifestasi lewat ragam hias ornamen. Bentuk ornamen yang ada masih merupakan bentuk hakiki yang dimiliki oleh bentuk acuannya seperti bentuk fauna, flora dan bentuk lainnya yang ada di alam. Biasanya bentuk ornamen yang mengacu dari bentuk hewan disebut kekarangan sedangkan ornamen yang bentuk acuannya berasal dari tumbuh-tumbuhan disebut pepatraan.

Ragam hias yang tergolong pepatraan merupakan ragam hias yang diwujudkan dalam pola berulang maupun pola berkembang. Selain pepatraan yang asli dari Bali, yang ditandai dengan penamaan jenis tanaman lokal, terdapat juga pepatraan yang menggunakan penamaan yang diambil dari nama negara lain. Menurut Gelebet (1981/1982:333) untuk menamai pepatraan digunakan nama jenis floranya, atau kemungkinan dari negara asalnya. Salah satu pepatraan yang namanya menggunakan nama negara luar Indonesia adalah patra Cina (Gbr 01).

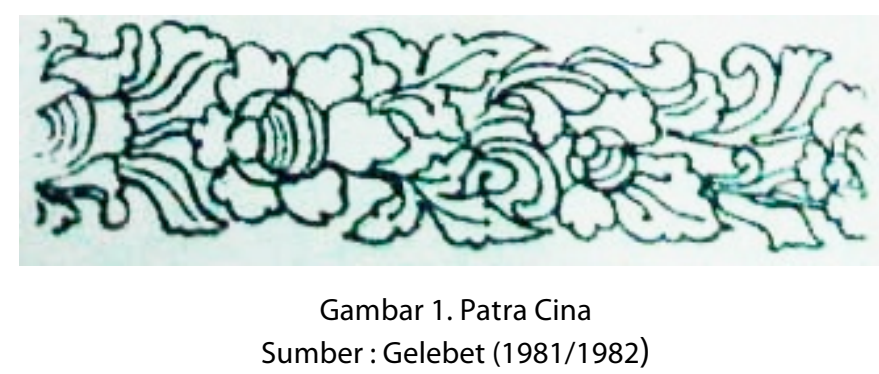

Bila dilihat dari bentuknya, sulit membedakan antara patra cina dengan patra-patra lain yang ada di Bali, karena konsep bentuk maupun polanya hampir sama dengan bentuk patra lainnya. Akan tetapi, patra cina menjadi salah satu bukti produk akulturasi budaya di Bali yang hingga kini masih digunakan. Patra cina juga merupakan salah satu produk 
pencerminan bagaimana budaya Bali menerima budaya asing masuk ke wilayahnya.

\section{METODE PENELITIAN}

Metode penelitian yang digunakan adalah kualitatif interpretatif. Menurut Ratna (2010: 94) secara etimologis, kualitatif (qualitative) berasal dari kualitas (quality) yang berarti nilai. Analisis menggunakan metode kualitatif ini digunakan berdasarkan pernyataan Kant (dalam Ratna, 2010:90) yang menyatakan bahwa objek ilmu-ilmu non empiris, ilmu ideografis merupakan kenyataan noumenal yang dapat dianalisis menggunakan metode kualitatif. Dalam hal ini ornamen patra cina merupakan suatu simbol yang digunakan masyarakat Bali sebagai salah satu artefak yang mengandung nilai- nilai filosofis menyangkut sistem budaya masyarakatnya. Sedangkan interpretasi menurut Ratna (2010) sesuai hakikatnya berisi penafsiran itu sendiri, dan menguraikan segala sesuatu yang ada di balik data yang ada, dengan kualitas objektivitas yang dibuktikan dengan cara pemahaman, mengaitkan objek dengan referensi - referensi yang relevan.

Metode kualitatif interpretatif digunakan untuk menguraikan setiap elemen pembentuk ornamen, kemudian dikaitkan dengan pola rasionalitas budaya Bali sebagai referensi. Sebagai data pendukung, ornamen patra cina dikaitkan dengan sejarah keberadaan bangsa cina di Bali.

\section{PEMBAHASAN}

\section{Pola Rasionalitas Masyarakat Bali}

Produk atau artefak hasil kebudayaan Bali merupakan produk budaya yang mengandung nilai filosofis tinggi, yang memuat pola rasionalitas masyarakatnya.

Menurut Sumardjo (2010), pola pemikiran masyarakat Bali mengacu pada pola lima. Pada Babad Pasek diceritakan peristiwa-peristiwa yang menandakan keseimbangan hidup pada pola tersebut. Diantaranya lima gunung yang menjaga keseimbangan pulau Bali, dan lima raja yang menyejahterakan rakyatnya.

Selain mengacu pada pola lima, kehidupan masyarakat Bali juga mengacu pada pola tiga (Gbr 02). Hal tersebut dapat dilihat dari pola yang dianut seperti: Triloka (Bhur Loka, Bhuwah Loka, Swah Loka), Tri Murti (Brahma, Wisnu, Siwa), Tri Angga (kaki, badan, kepala), Tri Pramana (jiwa, gerak, daya pikir) dan sebagainya. Ketiga bagian dalam pola tersebut merupakan suatu hubungan vertikal maupun horizontal yang saling melengkapi. Disini terdapat dualitas yang disatukan oleh satu bagian yang terletak diantaranya, oleh karena itu pola ini 
terdiri dari tiga bagian. Tiga menjadikan semuanya seimbang, menjadi satu, antara atas dan bawah, antara sakral dan nista. Seperti yang dikatakan Sumardjo (2010:261), bahwa estetika pola tiga merupakan hal yang saling bertolak belakang kemudian disatukan atau diharmonisasikan dengan dunia tengah, sehingga menjadi tiga.

Kembali pada Babad Pasek, diceritakan bahwa untuk menghentikan kegoyangan yang terjadi di pulau Bali (pada saat itu di Bali sudah terdapat lima gunung)Bhatara Pasupati kemudian membongkar lereng gunung Mahameru yang kemudian dipindahkan ke Bali yang kemudian menjadi gunung Agung, dan setelah itu posisi pulau Bali tidak goyang. Setelah lereng gunung Mahameru dipindahkan ke Bali, maka jumlah gunung yang ada di Bali menjadi enam buah. Hal tersebut juga dapat diasumsikan sebagai pola tiga yang berulang, yaitu tiga ditambah tiga, menjadi enam.

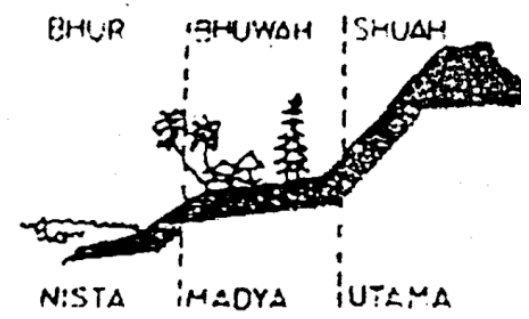

Gambar 2. Pembagian Alam (konsep triloka) Sumber: (Othman, 2004)

\section{Sejarah Patra Cina di Bali}

Pada masa Bali purbakala, pengaruh asing sulit sekali ditemukan. Seperti yang dikatakan Kempers (1956:6) bahwa pada masa Bali purbakala, jarang sekali ditemukan kebudayaan islam, terlebih kebudayaan Eropa. Mengenai pengaruh budaya Cina, dikatakan Kempers (1956:6), bahwa pengaruh budaya cina telah menyatu dengan budaya lokal Bali sehingga sulit dibedakan lagi.

Desa tradisional tertua di Bali diperkirakan telah ada sejak dua abad SM yang nenek moyangnya berasal dari keluarga Austronesia (Mulono dalam Dwijendra:2009) dan dikenal dengan sebutan Bali Aga (Bali pra Hindu). Menurut Dwijendra (2009:3) perbedaan antara Bali Aga dan Bali Apanaga terutama dari faktor geneologis dan faktor budaya, perbedaan 
geneologis, yaitu orang Bali Aga adalah termasuk ke dalam Bali Apanaga ditambah dengan orang Bali keturunan Mongoloid, sedangkan orang Bali Apanaga atau orang Bali dataran Jawa Hindu yang datang ke Bali melalui persebaran penduduk ekspedisi, seperti ekspedisi Singasari tahun 1284 M dan ekspedisi Gadjah Mada tahun 1343.

Dalam bentuk kesenian, akulturasi budaya cina dan Bali terlihat pada salah satu kesenian tradisional Wayang Landong. Wayang ini menceritakan mengenai pernikahan antara seorang raja bernama Jaya Pangus dengan seorang wanita cantik asal Cina Kang Tjin We. Hal ini merupakan simbol pemersatu antara Bali dengan Cina pada saat itu. Akulturasi budaya yang disimbolkan dengan pernikahan antar bangsa tersebut menurut Santosa (dalam Kompas.com) terjadi pada abad ke-12. Jadi, jika dilihat dari waktu cerita mengenai perkawinan raja ini dengan ekspedisi Singasari dan Gadjah Mada, maka akulturasi antara Bali dengan Cina sudah berlangsung sejak jaman pra Hindu.

Sedangkan kesejarahan yang berhubungan langsung dengan patra Cina dikemukakan oleh Sulistyawati dalam tulisannya yang berjudul "Intergrasi Arsitektur Tionghoa ke dalam Arsitektur Puri Agung Karangasem". Sulistyawati mengemukakan bahwa Puri Almapura atau yang disebut Puri Amsterdam, Karangasem sengaja dibangun sebagai simbol dari akulturasi antara Cina dan Bali yang termanifestasi lewat oranamen Cina (1900-1920). Ornamen tersebut dipahatkan pada salah satu bangunannya pertama kali oleh seorang seniman Cina yang bernama Cik A Tuang. Ornamen tersebut yang kini dikenal dengan sebutan patra Cina. Dikatakan pula bahwa patra Cina tersebut merupakan hasil kreasi dari Cik A Tuang dengan ornamen khas Bali.

Kalam dalam Sulisyawati, menjelaskan bahwa patra cina merupakan stiliran dari Kembang Sepatu yang dalam pengolahan batang, daun dan bunganya dibuat tegas sehingga mencerminkan pola yang kontruktif. Di Bali, Kembang Sepatu digunakan sebagai Kalpika/ Kartika yaitu perlengkapan yang selalu digunakan Sulinggih(orang terhormat yang biasa memimpin upacara) sebagai penyelesaian upacara. Kartika dibuat dari sehelai daun kembang sepatu dan bunga nya berwarna merah dan bunga Jepun (kamboja) yang berwarna putih. Daun Kembang Sepatu dilipat sehingga membentuk segi empat belah ketupat, membungkus bunga jepun dan Kembang Sepatu. Warna Kalpika melambangkan : Trimurti : warna hijau/ hitam melambangkan Wisnu, warna merah melambangkan Brahma dan putih melambangkan Siwa. 
Kembang Sepatu (Hibiscus Rosa-Sinensis L) merupakan perdu yang menyerupai pohon, tumbuh di daerah tropis dan sub tropis (Mininger dalam Kirana, 1990) (Gbr 03). Kembang Sepatu merupakan hasil hibridisasi yang banyak dibudidayakan di pulau Jawa. Mengenai asal dari tumbuhan ini, Brink Jr.(1963) mengemukakan bahwa tumbuhan ini bisa saja berasal dari Cina, hal ini diperkuat dari sebutan tanaman ini sebagai China Rose Flower yang berasal dari asia timur.

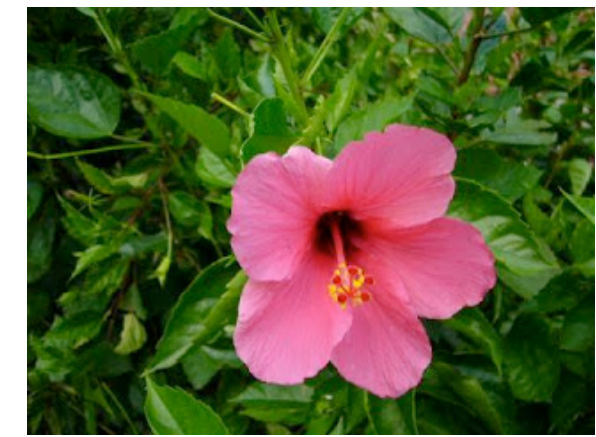

Gambar 3.Kembang Sepatu Sumber : www.wikipedia.com

\section{Penerapan Patra Cina sebagai Elemen Dekorasi}

Patra cina biasa digunakan oleh masyarakat Bali sebagai ornamen pada bangunan tradisional Bali, salah satunya di Pura (Gbr 04). Pola rasionalitas masyarakat Bali tercermin dari bentuk arsitekturnya, terutama pada bangunan yang ada di pura. Pola tersebut tercermin dari pembagian bangunan kedalam tiga bagian, yaitu bagian bawah yang tidak sakral (nista/ tepas), bagian tengah (madya/batur), dan bagian atas (utama/sari) yang merupakan bagian tersakral. Pada bangunan di pura, ornamen patra cina dapat ditempelkan pada bagian bawah, tengah, atau atas bangunan. Patra ini hanya bersifat dekoratif dan digunakan sebagai salah satu simbol makhluk hidup (tumbuhan/flora) ciptaan Sang Hyang Widhi Washa. 


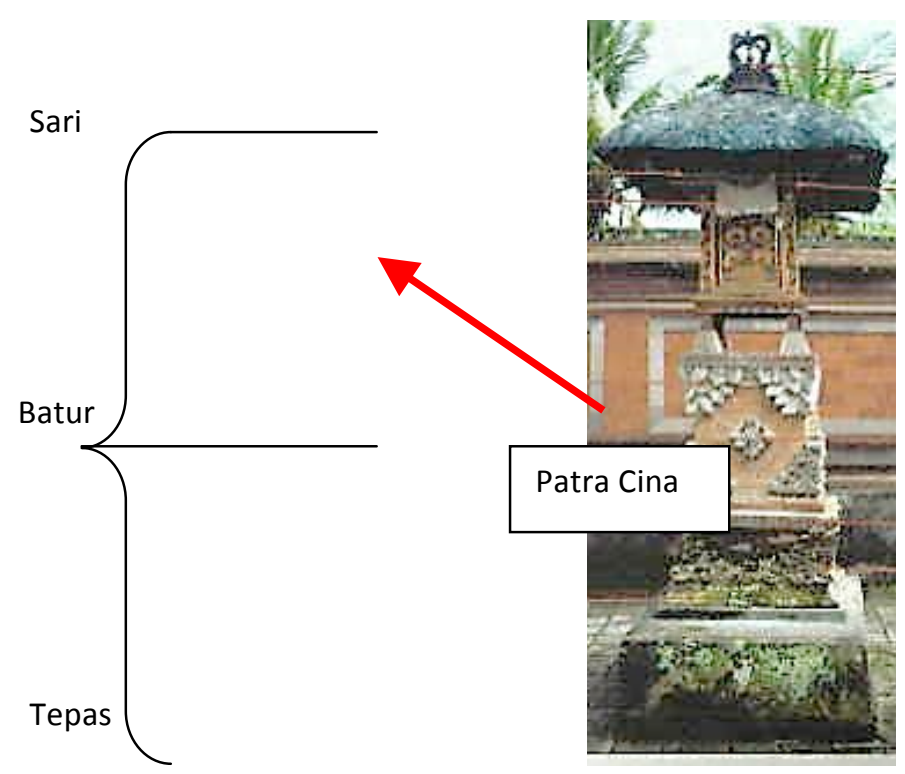

Gambar 4. Penerapan Patra Cina pada Bangunan Pelinggih Taksu di Pura Sumber : Saja (2009)

Selain sebagai ornamen di bangunan tradisional Bali, patra cina juga biasa digunakan oleh pengrajin tradisional Bali sebagai elemen dekoratif pada ukiran- ukiran Bali. Ukiran tersebut dapat berbahan kayu, tulang hewan maupun tanduk Rusa. Ornamen patra cina biasanya digunakan sebagai dekorasi dari ukiran utama berupa tokoh pewayangan. Menurut Seraya (1995), pengrajin asal Tampaksiring banyak menggunakan ornamen patra cina sebagai hiasan dari ukiran tokoh pewayangan yang dibuat.

\section{Analisis Bentuk Ornamen Patra Cina}

Patra cina (Gbr 06) merupakan salah satu ornamen pepatraan yang menggunakan nama negara asing yang digunakan oleh masyarakat Bali.

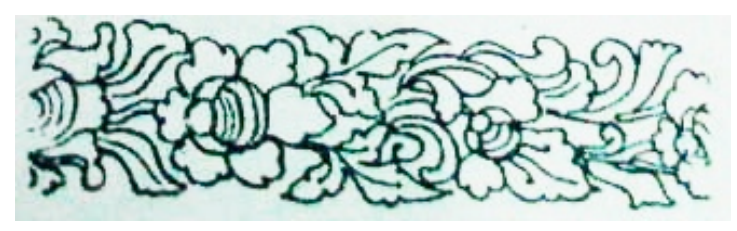

Gambar 5. Patra Cina

Sumber : Gelebet (1982)

Seperti pepatraan yang lain, pola berulang yang diterapkan pada setiap pepatraan juga ditemukan pada patra cina. Oleh karena itu terdapat pola dasar yang kemudian diulang dengan pertimbangan estetika. Berdasarkan pola rasionalitas masyarakat Bali yang mengacu pada pola 3, ornamen patra cina juga menggunakan pola 3 sebagai acuan. Hal 
tersebut dapat terlihat pada jumlah kelopak bunga, helai daun, dan bentuk sulur maupun batangnya. Prinsip penyatuan dualitas yang saling bertolak belakang disatukan oleh dunia tengah menghasilkan pola yang mengacu dari jumlah, yaitu 3, maupun dari bentuk, seperti bentuk " $\mathrm{C}$ " dan bentuk "S".

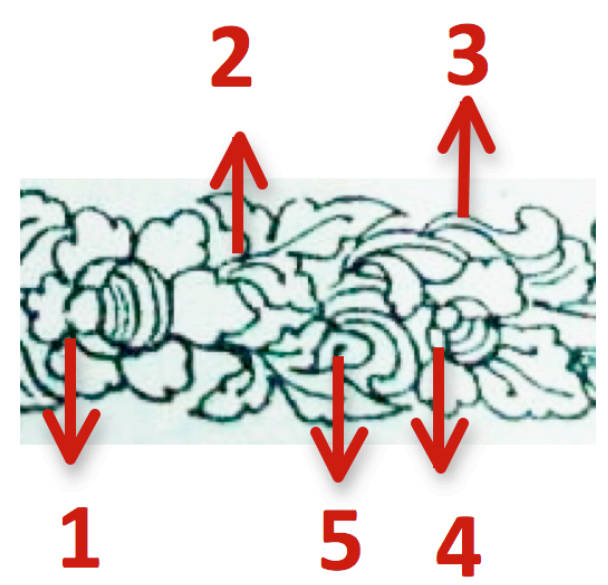

\section{Gambar 6.Analisis bentuk Patra Cina} Sumber : Penulis (2017)

Pada gambar di atas (Gbr 07), ornamen patra cina dibagi menjadi lima bentuk dasar yang kemudian menjadi sebuah pola berulang. Analisis bentuk dan pola tersebut dipaparkan menggunakan pola rasionalitas masyarakat tradisional Bali sesuai dengan teori yang dikemukakan oleh Sumardjo (2010) mengenai estetika pola tiga.

Keterangan :

No.1 merupakan bentuk bunga yang memiliki kelopak sebanyak 6 buah (Gbr 08). Jika dikaitkan dengan pola rasionalitas masyarakat Hindu Bali yang sebagian besar menggunakan pola tiga, maka dapat diasumsikan bahwa jumlah kelopak merupakan pengulangan dari pola 3.

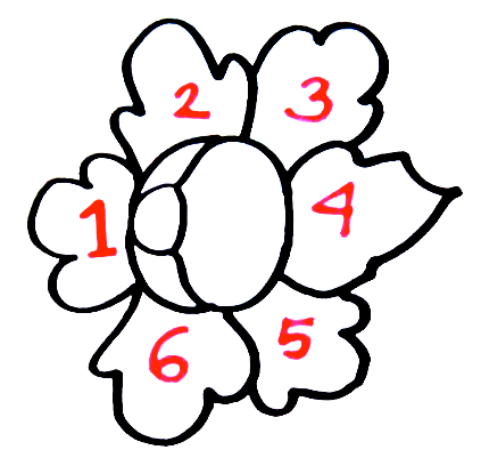

Gambar 7.Analisis bentuk Patra Cina no.1 Sumber : Penulis (2017) 
No. 2 merupakan bentuk daun dengan bagian tulangnya terbagi menjadi tiga bagian (Gbr 09). Hal ini juga menggambarkan pola 3 sebagai pola rasionalitas masyarakat Hindu Bali.

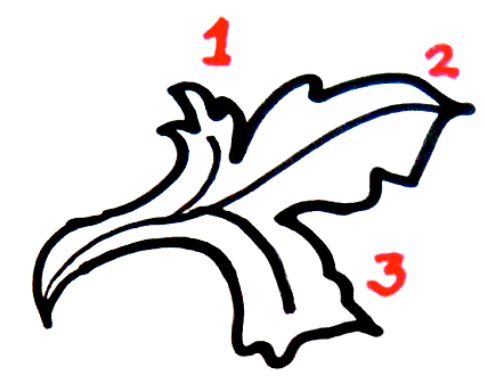

Gambar 8.Analisis bentuk Patra Cina no.2 Sumber : Penulis (2017)

No. 3 merupakan bentuk sulur pada tanaman yang membentuk pola huruf "S" (Gbr 10). Menurut Sumardjo (2010:223), pola "S" merupakan motif paling tua di Indonesia. Dalam hal ini, huruf "S" merupakan paradoks antara dualitas yang dipahami oleh sebagian besar masyarakat Indonesia termasuk Bali. Dalam pemahaman masyarakat Indonesia, sesuatu yang paradoks itu harus disatukan, diseimbangkan sehingga kehidupan akan bahagia dan sejahtera.

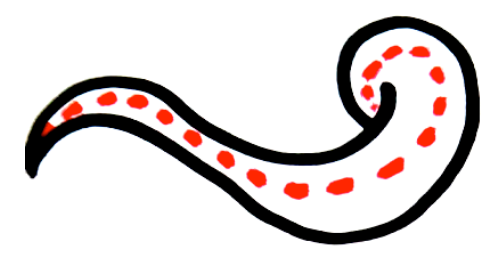

Gambar 9 .Analisis bentuk Patra Cina no.3 Sumber : Penulis (2017)

No. 4 merupakan bentuk bunga yang memiliki kelopak sebanyak 3 buah (Gbr 11). Bunga ini memiliki ukuran yang lebih kecil dibandingkan dengan bunga sebelumnya.

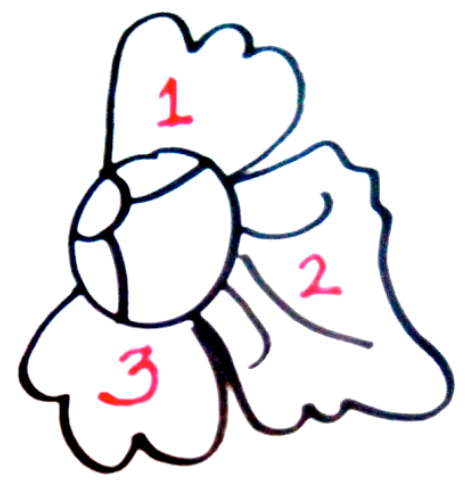

Gambar 10.Analisis bentuk Patra Cina no.4 Sumber : Penulis (2017) 
No. 5 merupakan bentuk sulur yang bila dilihat membentuk huruf " $C$ " (Gbr 12). Menurut Sumardjo (2010:223) huruf " $C$ " dalam pola pemahaman masyarakat tradisional yang banyak digunakan sebagai hiasan dari desain abstrak yang merupakan pola "kesatuan-berbalikan". Dari analisis pola dasar bentuk yang terdapat pada patra cina, ditemukan estetika pola tiga yang tercermin dalam jumlah kelopak bunga, bentuk sulur dan daun. Pola tiga yang esensinya menyatukan paradoks, diterapakan juga pada bentuk sulur yang membentuk huruf " $S$ " dan huruf "C" pada setiap bentuk dasar patra Cina.

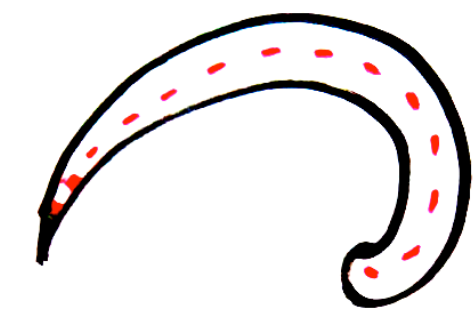

Gambar 11.Analisis bentuk Patra Cina no.5 Sumber : Penulis (2017)

\section{PENUTUP}

Patra cina merupakan produk multikultur, perpaduan antara budaya tradisional Bali dan cina. Patra cina dibuat oleh orang keturunan Cina, akan tetapi struktur pola ornamen menggunakan pola rasionalitas masyarakat tradisional Bali, dengan menggunakan bentuk Kembang Sepatu yang berasal dari Cina sebagai simbol persatuan antara budaya Bali dengan Cina. Dalam analisis bentuk, patra Cina memiliki pola dasar tradisional Indonesia, yakni pola tiga dilihat dari jumlah kelopak bunga dan daun yang ada pada ornamen, pola lima dilihat dari banyaknya bentuk dasar ornamen, pola huruf " $\mathrm{S}$ ", dan pola huruf "C yang banyak digunakan pada pola tradisional Indonesia.

Dengan adanya pemaparan mengenai studi multikultur yang ada pada ornamen patra cina, diharapkan dapat memberikan kontribusi bagi perkembangan khasanah ilmu pengetahuan dan budaya dalam pembacaan pola ornamen tradisional Indonesia yang di dalamnya terkandung makna simbolik yang mewakili pola pikir suatu kelompok masyarakat.

\section{DAFTAR PUSTAKA}

Backer,Brink Jr.(1963). Flora of Java (spermatophytes only). New York : N.V.P. NoordhoffGroningen- The Netherlands 
Dwijendra,N.K.A. (2008) Arsitektur Bangunan Suci Hindu Berdasarkan Asta Kosala-Kosali. Denpasar: Udayana University Press.

--------(2009).Arsitektur \& Kebudayaan Bali Kuno. Denpasar: Udayana University Press

Gelebet, I Nyoman, dkk.(1981/1982) Arsitektur Tradisional Daerah Bali. Bali: Departemen Pendidikan dan Kebudayaan Proyek Inventarisasi dan Dokumentasi Kebudayaan Daerah

Kempers.(1956).Bali Purbakala.Jakarta: Balai Buku Indonesia.

Kirana, Myrna. C. (1990) Ragi Hasil Isolasi dari Kembang Sepatu (Hibiscus Rosa-Sinensis. L) yang Mempunyai Kemampuan Melakukan Fermentasi Alkoholik. Tesis. Bandung: Institut Teknologi Bandung.

Othman, Moh. Nor.(2004). Unsur-Unsur Pada Rumah Tinggal Melayu Di Selangor Malaysia. Thesis- Program Magister Desain Program Pasca Sarjana. Institut Teknologi Bandung. Bandung.

Ratna, Nyoman Kutha.(2010) Metodelogi Penelitian: Kajian Budaya dan Ilmu-ilmu Sosial Humaniora pada Umumnya. Yogyakarta: Pustaka Pelajar

Saja, Nyoman.(2009 )Klasifikasi Ornamen Bali Sebagai Referensi Pembuatan Game (Studi Kasus Pura Taman Pule Desa Mas Ubud, Gianyar-Bali). Tesis. Program Studi Magister Desain Fakultas Seni Rupa dan Desain Institut Teknologi Bandung. Bandung

Seraya, I Made, I Ketut Mas dan I Made SuparthaEndraKusuma. (1995).Pengerajin Tradisional di Daerah Bali. Direktorat Jendral Kebudayaan.

Sumardjo, Jakob.(2010).Estetika Paradoks. Bandung: Sunan Ambu Press

Santosa, Iwan.,Sulistyowati,Ayu.Pemersatu Bali-Tionghoa. Diunduh 16 Oktober 2017 dari www.nasional.kompas.com

Sulistyawati. Integrasi Arsitektur Tionghoa ke dalam Arsitektur Puri Agung Karangasem.

Diunduh 16 Oktober 2017 dari <www.profsuli.files.wordpress.com> 